\title{
From meta-system theory to the sustainable management of rivers in the Anthropocene
}

\author{
Núria Cid $^{1^{*}}$, Tibor Erös ${ }^{2}$, Jani Heino ${ }^{3}$, Gabriel Singer ${ }^{4}$, Sonja C Jähnig ${ }^{5,6}$, Miguel Cañedo-Argüelles ${ }^{7,8}$, Núria Bonada ${ }^{7,9}$, \\ Romain Sarremejane $^{1}$, Heikki Mykrä ${ }^{3}$, Leonard Sandin ${ }^{10}$, Riikka Paloniemi ${ }^{11}$, Liisa Varumo ${ }^{11}$, and Thibault Datry ${ }^{1}$
}

Regional-scale ecological processes, such as the spatial flows of material, energy, and organisms, are fundamental for maintaining biodiversity and ecosystem functioning in river networks. Yet these processes remain largely overlooked in most river management practices and underlying policies. Here, we propose adoption of a meta-system approach, where regional processes acting at different levels of ecological organization - populations, communities, and ecosystems - are integrated into conventional river conservation, restoration, and biomonitoring. We also describe a series of measurements and indicators that could be assimilated into the implementation of relevant biodiversity and environmental policies. Finally, we highlight the need for alternative management strategies that can guide practitioners toward applying recent advances in ecology to preserve and restore river ecosystems and the ecosystem services they provide, in the context of increasing alteration of river network connectivity worldwide.

Front Ecol Environ 2021; doi:10.1002/fee.2417

$\mathrm{R}$ iver ecosystems sustain disproportionate levels of biodiversity at landscape, regional, and continental scales (Reid et al. 2019). They contribute substantially to global biogeochemical

\section{In a nutshell:}

- Rivers are hotspots of biodiversity and provide essential ecosystem functions and services, but face numerous threats globally

- Understanding of how rivers are organized across spatial scales has progressed considerably over the past several decades, proving that regional-scale processes are vital for preserving population, community, and ecosystem dynamics

- However, most existing river conservation, restoration, and biomonitoring practices focus on local-scale strategies and measures

- To improve the management of river networks in the Anthropocene, we suggest additional metrics and assessment approaches that incorporate regional processes more effectively

\footnotetext{
${ }^{1}$ INRAE, UR RiverLy, Centre de Lyon-Villeurbanne, Villeurbanne Cedex, France* (nuria.cid-puey@inrae.fr; nuria.cid@irta.cat); ${ }^{2}$ Balaton Limnological Research Institute, Tihany, Hungary; ${ }^{3}$ Finnish Environment Institute, Freshwater Centre, Oulu, Finland; ${ }^{4}$ Department of Ecology, University of Innsbruck, Innsbruck, Austria; ${ }^{5}$ Leibniz Institute of Freshwater Ecology and Inland Fisheries, Department of Ecosystem Research, Berlin, Germany; ${ }^{6}$ Geography Department, Faculty of Mathematics and Natural Sciences, Humboldt-Universität zu Berlin, Berlin, Germany; ${ }^{7}$ Freshwater Ecology, Hydrology and Management Research Group, Departament de Biologia Evolutiva, Ecologia i Ciències Ambientals, Facultat de Biologia, Universitat de Barcelona, Barcelona, Spain; ${ }^{8}$ Institut de Recerca de l'Aigua, Universitat de Barcelona, Barcelona, Spain; (continued on last page)
}

cycles through release of carbon dioxide to the atmosphere and transport of carbon and nutrients from continents to oceans (Raymond et al. 2013). Rivers also provide key ecosystem services, including provision of drinking water, food production, and climate and water regulation, which are critical to sustaining human wellbeing (Reid et al.2019). However, in the current Anthropocene era (Panel 1), rivers worldwide are increasingly impaired by human activities, and are now among the most threatened ecosystems on Earth (Dudgeon 2019). This global trend necessitates the development of more effective management strategies and policies to ensure maintenance of the biodiversity and functional integrity of river ecosystems in the future.

Most river management practices, independently of the spatial scale at which they are implemented, are based on local assessments, as a legacy of the niche paradigm that has prevailed in ecology for decades (Panel 1; Heino 2013). In contrast, scientific understanding of how biodiversity, ecosystem functions, and ecosystem services are organized across river networks has progressed considerably with the emergence of meta-system theory (Gounand et al. 2018). This framework acknowledges that both local (ie niche selection and biotic interactions within a river reach) and regional (ie dispersal of organisms and spatial flows of material and energy across the river network) mechanisms interact to shape the spatial and temporal organization of populations and communities, and drive ecosystem processes and services. The meta-system framework is particularly relevant for river networks due to their dendritic topology (Panel 1) and the predominantly unidirectional flow of water, which constrain the exchange of matter and organisms at larger spatial scales (Tonkin et al. 2018). Current river management practices and underlying policies often fail to incorporate important regional processes, hindering efficient conservation and 


\section{Panel 1. Glossary of terms}

Alpha diversity: diversity within a specific ecosystem or area (the local species richness), usually expressed as the number of species present (Whittaker 1972).

Anthropocene: a new, human-dominated geological epoch that began somewhere between the years 1610-1964, depending on different lines of evidence (Lewis and Maslin 2015).

Beta diversity: quantification of the number of different communities in a region measured as extent of change (Whittaker 1972).

Dendritic structure (in river networks): rivers and streams follow a geometric pattern of arborescent bifurcation originating from one node and extending out in one direction, forming a hierarchical network of nodes and branches (Heino 2013).

Dispersal: movement of individuals from one locality to another (Leibold et al. 2004).

Niche: range of resource availability and physical conditions that a given species can tolerate to survive at a locality (Leibold et al. 2004).

Metapopulation: a set of local populations of a single species that are linked by dispersal (Hanski 1998).
Metacommunity: a set of local communities that are linked by dispersal of multiple potentially interacting species (Leibold et al. 2004).

Meta-ecosystem: a set of ecosystems connected by spatial flows of energy, material, and organisms across ecosystem boundaries (Gounand et al. 2018).

Regional diversity (gamma diversity): total diversity within the entire landscape (ie regional species pool; Whittaker 1972).

Service-providing areas: spatial units that are the sources of ecosystem services in a given landscape (Syrbe and Walz 2012).

Service-connecting areas: spatial units connecting providing areas with benefiting areas in a given landscape (Syrbe and Walz 2012).

Service-benefiting areas: spatial units where the benefits from ecosystem services are required in a given landscape (Syrbe and Walz 2012).

Zeta diversity: number of species shared by multiple communities (Simons et al. 2019). restoration of river biodiversity and ecosystem functions (Erős et al. 2018).

Management practices that focus solely on the local scale will increasingly be less effective for achieving desired ecological outcomes. Globally, humans modify catchments through land-use changes; flow regulation by dams, water diversion, and extraction of surface and ground water; and pollution and the introduction of invasive species (Dudgeon 2019). Fragmentation by dams is the major driver of connectivity loss (Grill et al. 2019), a process exacerbated by climate-changerelated increases in the intensity and frequency of droughts and subsequent drying of river networks (Döll and Schmied 2012). In areas where human population densities are high, the flow regimes of streams and rivers have been altered to such a degree that "novel" ecosystems have been created (Datry et al. 2018). Despite having local impacts, most anthropogenic threats at present act at regional or global scales (Dudgeon 2019). Overall, the increasing pressure of multiple threats calls for a better integration of scale-dependent approaches to guide water management and conservation policies in a changing world.

Our primary objective here was to translate meta-system theory into real-world management and policy recommendations for rivers. To do so, we first present the meta-system framework and its relevance for river ecosystems, particularly with respect to decreased connectivity resulting from humaninduced fragmentation; we then show why this framework can inform river management to effectively achieve environmental and conservation targets; and finally, we identify specific policy implications and provide guidance on how a meta-system approach could be implemented.

\section{Meta-system theory and its relevance in river networks}

Essentially, meta-system theory states that local- and regionalscale processes interact to influence the dynamics of environmental conditions and biota in a given landscape (Figure 1; Gounand et al. 2018). Regional-scale processes determine fluxes of individuals, species, and material and energy among local populations, communities, and ecosystems, respectively, whereas local-scale dynamics represent interactions with abiotic conditions and other species (Hanski 1998; Leibold et al. 2004; Gounand et al. 2018). In turn, sets of local populations, communities, and ecosystems linked by regional fluxes form metapopulations, metacommunities, and meta-ecosystems, respectively (Panel 1; Figure 1). In river networks, dispersal of organisms can be constrained by the dendritic topology, flow regime, physical barriers, and dispersal ability of the organisms, leading to spatial variation among populations and communities (Brown et al. 2011). Matter and energy vary spatially, as sources of terrestrial inputs are differentiated across subcatchments (Creed et al. 2015) and upstream-to-downstream physical linkage dominates transport with en-route biogeochemical modulation. Such spatial dynamics in the flows of matter and organisms at the regional subcatchment scale can 
determine riverine ecosystem functioning at the local reach scale. Meta-system theory upgrades the perspectives of metapopulation and metacommunity ecology in river ecosystems focused on spatial flows of organisms by incorporating those of resources, material, and energy (Gounand et al. 2018). It offers a framework for gaining a better understanding of the spatial coupling of biodiversity dynamics and ecosystem functioning, eventually contributing to ecosystem services (Gounand et al. 2018), and it reinforces previous research on ecological processes across spatial scales in river networks (Fausch et al. 2002; Brown et al. 2011; McCluney et al. 2014). By explicitly distinguishing the different levels of ecological organization, it also provides a robust structure for implementing current biodiversity and environmental policies.

The relevance of the meta-system framework for improving river management can be illustrated through fragmented river networks. Fragmentation, by weirs, dams, or channel drying, not only alters the local environment and biota (eg Datry et al. 2014) but also disrupts the fluxes of water, resources, and organisms

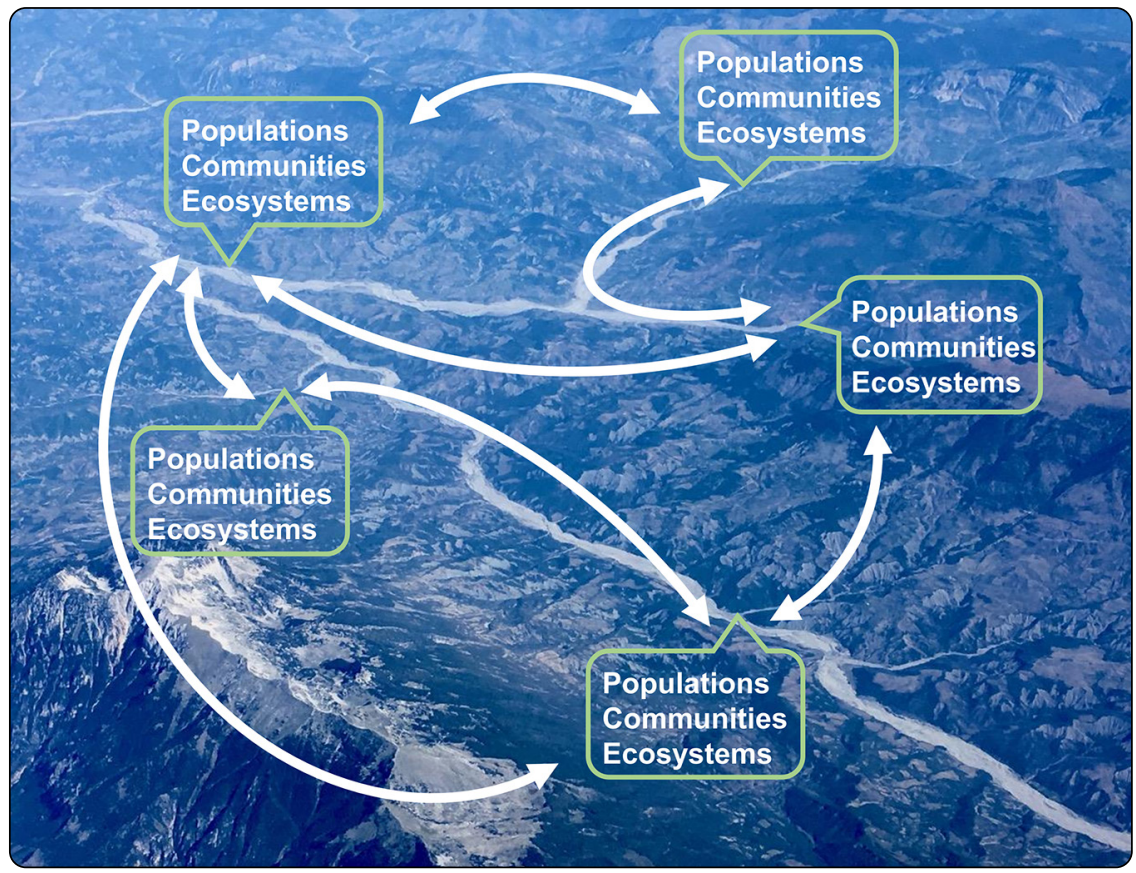

Figure 1. Schematic representation of metapopulations, metacommunities, and metaecosystems in a drying river network. Local populations, communities, and ecosystems (green rectangles) are connected by gene flow, dispersal of individuals, and flow of resources (white arrows), respectively, across the landscape.

\section{(Gounand et al. 2018; Grill et al. 2019). The} effects of fragmentation cascade across organizational levels, from populations to ecosystems and eventually to socioecological systems, with detrimental effects on the provision of ecosystem services (Figure 2). Fragmentation can isolate local populations and reduce gene flow within a metapopulation, jeopardizing their long-term persistence due to genetic drift and inbreeding (Fitzpatrick and Reid 2019). Ultimately, this can lead to reductions in species ranges and eventually to local or regional extinctions (Hanski 1998). Responses to the fragmentation of metapopulations cascade to altered metacommunity dynamics. Reduced dispersal among isolated local communities can lead to shifts in community composition, biodiversity patterns, and biological interactions at local and regional scales (Jaeger et al. 2014), transforming ecosystem functions (Gounand et al. 2018). Fragmentation can also have direct effects on fluxes of material (Figure 2). For example, drying resulting from excessive water abstraction, dam construction, or climate change can alter the storage and transport of coarse organic matter and nutrients in the network, as these are retained at sites without flow before subsequent massive releases at flow resumption (Datry et al. 2018). Fragmentation may ultimately impact ecosystem service provision at the river basin scale by altering service-providing, service-connecting, and service-benefiting areas (Panel 1; Figure 2; Datry et al. 2017). Understanding regional processes occurring at each level of organization (ie metapopulation, metacommunity, and meta-ecosystem) can therefore be crucial for guiding effective river conservation, monitoring, and restoration.

\section{Integrating regional-scale processes in river conservation, restoration, and monitoring}

Meta-system theory can also help managers to better predict how populations respond to anthropogenic stressors at the regional scale, and consequently to design conservation plans accordingly (Schiesari et al. 2019). When a population follows source-sink dynamics, the regional persistence of the species primarily depends on key "source" populations that contribute via dispersal to "sink" populations (Hanski 1998). Identifying where these key populations and their main dispersal routes are located is crucial to ensure adequate species conservation. For instance, studies on salmonid fishes show that fragmentation by large reservoir dams, hatchery introductions, and deterioration of habitat quality can substantially alter metapopulation structure, and that optimal management strategies should be based on maintaining habitat quality and connectivity of key source populations (Fullerton et al. 2016). In very fragmented metapopulations, local populations decline, and the risk of extinction is higher than in large and connected metapopulations (Fitzpatrick and Reid 2019). For example, historically connected metapopulations of the endangered Iberian cyprinid fish Iberochondrostoma almacai now experience fragmentation as a result of river drying and are subjected to strong genetic drift (Sousa et al. 2010). Protecting local habitats alone would not be effective to sustain the species, and conservation strategies should target increasing gene flow (Sousa et al. 2010). On the contrary, historically isolated populations 


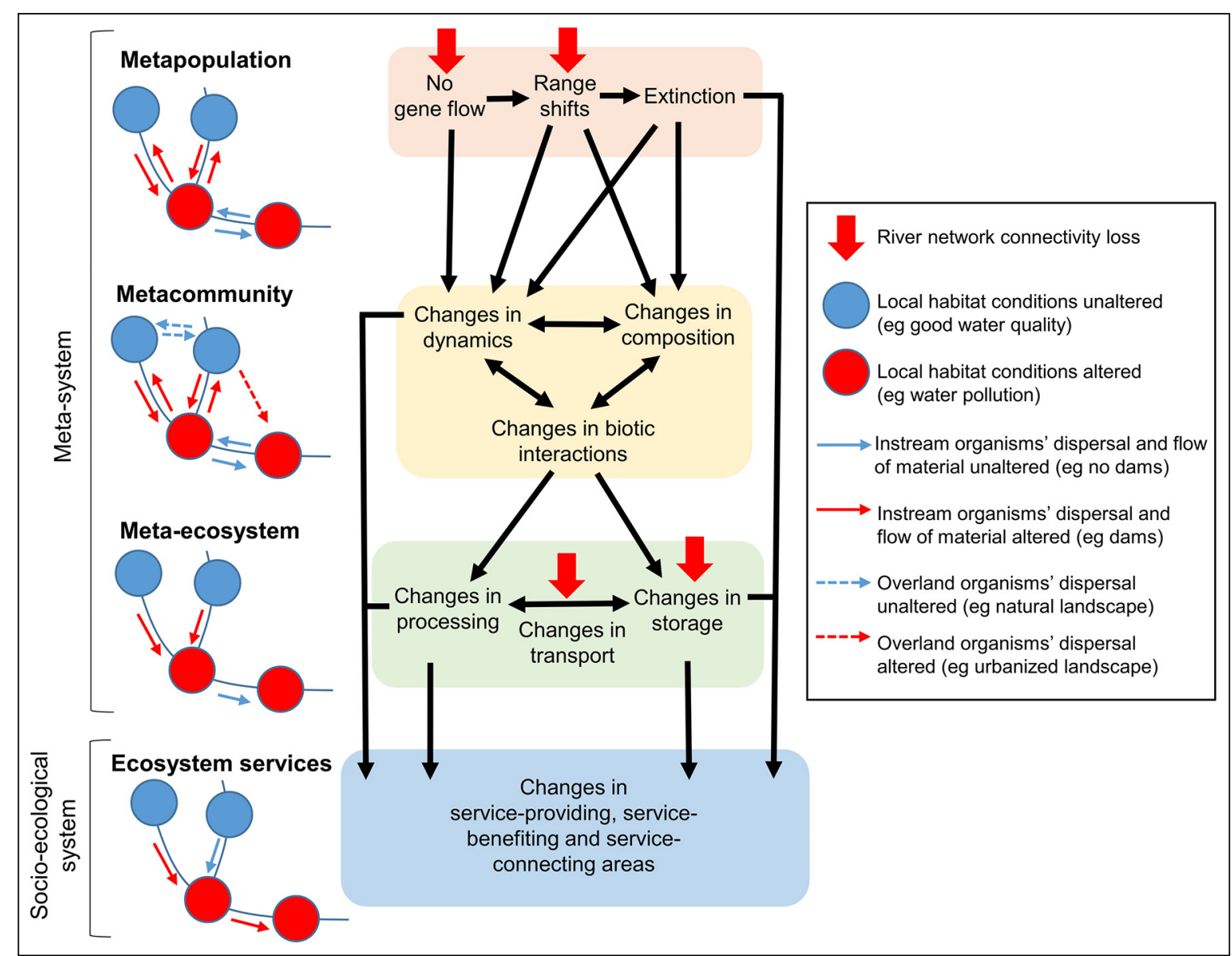

Figure 2. Conceptual diagram of the cascading effects of the alteration of river network connectivity across different levels of the meta-system (ie metapopulation, metacommunity, and meta-ecosystem) and the socioecological system (ie ecosystem services). Note that for ecosystem services, blue and red arrows represent the flow between service-providing and service-benefiting areas (Panel 1).

require careful management to maintain isolation-driven evolutionary processes at the landscape scale (Rahel and McLaughlin 2018). Information about population sizes, dispersal abilities, and physical distance among populations is necessary to distinguish among different metapopulation structures in landscapes, which require varying management strategies and priorities (Fullerton et al. 2016).

Regional-scale thinking is also critical for understanding the spread of invasive species (Strecker and Brittain 2017). In river networks, however, their management is still poorly developed and can be controversial (Chen and Olden 2017). For example, artificial barriers alter natural metapopulation dynamics but also can limit the spread of invasive fish (Rahel and McLaughlin 2018). In contrast, altering naturally intermittent flow regimes of river networks by artificially producing perennial flows can promote new invasions of alien species (Ruhí et al. 2019). Identifying the respective role of local and regional processes in the dynamics of invasive species relative to native ones is fundamental if undesired conservation and management effects are to be avoided (Rahel and McLaughlin 2018).

Considering metapopulation structure can improve predictions of species range shifts in response to climate change, as dispersal ability can determine whether species will be able to shift to new suitable regions and habitats (Markovic et al. 2014). However, most assessments based on species distribution modeling only consider the potential effects of climate change on local conditions (ie niche-based modeling). If the primary goal is to develop more resilient large-scale conservation strategies, then evaluation of species' vulnerability and extinction risk must incorporate dispersal-related processes, as well as the effects of projected river network fragmentation on biota (Markovic et al. 2017).

At the community level, information on metacommunity structure can be useful for guiding effective restoration and biomonitoring practices. Currently, most restoration projects may fail to achieve biodiversity and/or ecological quality targets because they are typically limited to the local scale (Tonkin et al.2014). For example, a reduced regional pool of colonizers could hamper achieving expected restoration targets in highly degraded catchments, where unimpacted sites (ie natural recolonization sources) are isolated due to fragmentation (Tonkin et al. 2014; Swan and Brown 2017). Similarly, biomonitoring methods to evaluate river health or ecological status may fail to detect anthropogenic impacts, mainly as a result of dispersal limitation (Heino 2013). Most biomonitoring methods assume that local communities respond to local environmental conditions identically, and that all species can eventually 
reach all sites (Cid et al. 2020). However, fragmentation can prevent species from reaching their optimal habitats, and isolated sites may present lower richness and bioassessment scores despite the presence of high-quality habitat (Heino 2013). In naturally intermittent river networks, although drying can generate habitat heterogeneity in terms of wet and dry habitats and thereby promote species richness, it can also increase fragmentation and prevent some species from colonizing a site, reducing local species richness (Datry et al. 2014). Applying the basic tenets of metacommunity ecology in biomonitoring and restoration practices can be helpful for determining the relative influence of local and regional processes on local community composition (Cid et al. 2020).

Metacommunity ecology uses a range of scale-sensitive biodiversity measures that are typically omitted from local biodiversity assessments based on alpha diversity (Panel 1). For example, beta diversity (Panel 1) and its components can be useful for identifying and preserving sites that contribute the most to maintaining regional diversity (Panel 1; Ruhí et al. 2017). Expanding the metrics used in routine assessments can provide essential data for evaluating metacommunity structure and function, and improve their conservation (Simons et al.2019).

Species in a metacommunity interact at local and regional scales (Hagen et al.2012), and biotic interactions can be altered by changes in hydrologic connectivity across a river network. For instance, fragmentation by dams can isolate freshwater mussel metapopulations from their host fish, on which they depend for completing their life cycles and dispersing across the network (Ferreira-Rodríguez et al. 2019), whereas fragmentation by drying can simplify food webs after the loss of top predators, having direct effects on ecosystem processes (Hagen et al. 2012). Identifying key biotic interactions across the meta-system will help attain biodiversity targets closely linked with ecosystem functioning (Hagen et al. 2012).

By modifying the flow of water, sediments, and organisms, fragmentation affects the fluxes of matter (minerals, carbon, nutrients) across river networks. For instance, current dam removal efforts benefit sediment transportation, counteract coastal erosion, and restore upstream movement of migratory fish, allowing transport of marine nutrients to isolated headwaters (Bellmore et al. 2019). Fragmentation can also lead to suboptimal ecosystem processes both locally and regionally if resources accumulate but organisms processing those are lacking, and vice-versa (Gounand et al. 2018). This might occur when natural drying of stream channels in intermittent rivers stops the transport of organic matter from upstream and subsequently limits ecosystem functioning downstream (Datry et al. 2018). Identifying when and where various kinds of matter (and energy) are processed and transported is essential for maintaining ecosystem functioning and services (Datry et al. 2017).

\section{Policy implications and management opportunities}

Biodiversity and environmental conservation are governed through several interlinked goals and agreements at the international and national levels. Global objectives, such as those stated in the Convention on Biological Diversity's Aichi Biodiversity Targets and the UN Sustainable Development Goals aiming for a more sustainable world, are reflected in international and national strategies and policies (Figure 3; Table 1). These policies are articulated and enforced through guidance documents, which include common implementation methodologies describing how to obtain indicator metrics for tracking progress toward environmental and conservation targets (Table 1). Below, we present several options for integrating regional-scale processes into the current local-scale management of river networks, focusing on biodiversity conservation, biomonitoring, and restoration. We also propose a series of alternative metrics and indicators (Table 1) that could complement such methodologies and sharpen strategies to guide efforts in reversing current trends of freshwater biodiversity loss and ecosystem degradation due to river fragmentation.

\section{Biodiversity conservation}

To determine the conservation status of species, conservation policies (such as the EU Habitats Directive or the US Endangered Species Act) rely in part on information obtained from population estimates, most of which only account for species population size and habitat quality (Table 1). Under a meta-system approach, methods and indicators capable of assessing metapopulation structure should be incorporated. This includes molecular tools and techniques for obtaining genetic diversity metrics to infer connectivity within a delimited spatial area (eg catchment or subcatchment) and/or direct measures of dispersal (Table 1) using mark-recapture or genetic methods (Fullerton et al. 2016). However, because empirical data on metapopulations are not always available to managers, monitoring efforts and sharing data should be encouraged. Such information could be integrated into individual-based models and thereby contribute to the identification of critical thresholds (Dudley 2018).

Responses for mitigating the effects of altered river network connectivity on biodiversity can be varied (Fuller et al. 2015). In general, when freshwater metapopulations experience a lack of gene flow, conservation actions should promote connectivity, for example through the removal of artificial barriers, installation of fish passages, or implementation of environmental flows (Poff et al. 2010). Despite efforts to shift environmental flow management from local to regional scales (eg Stewardson and Guarino 2018), most dam management practices remain focused on restoring flow regimes to river segments immediately downstream. Coordinated dam management across the river network would instead provide opportunities to increase connectivity and maintain meta-system dynamics (McCluney et al. 2014; Chen and Olden 2017). In a meta-system context, environmental flow management should target the conservation and restoration of variation in regional ecological features (eg through use of the metrics listed in Table 1). If increasing connectivity is not feasible via restoration, or if populations are too isolated to 


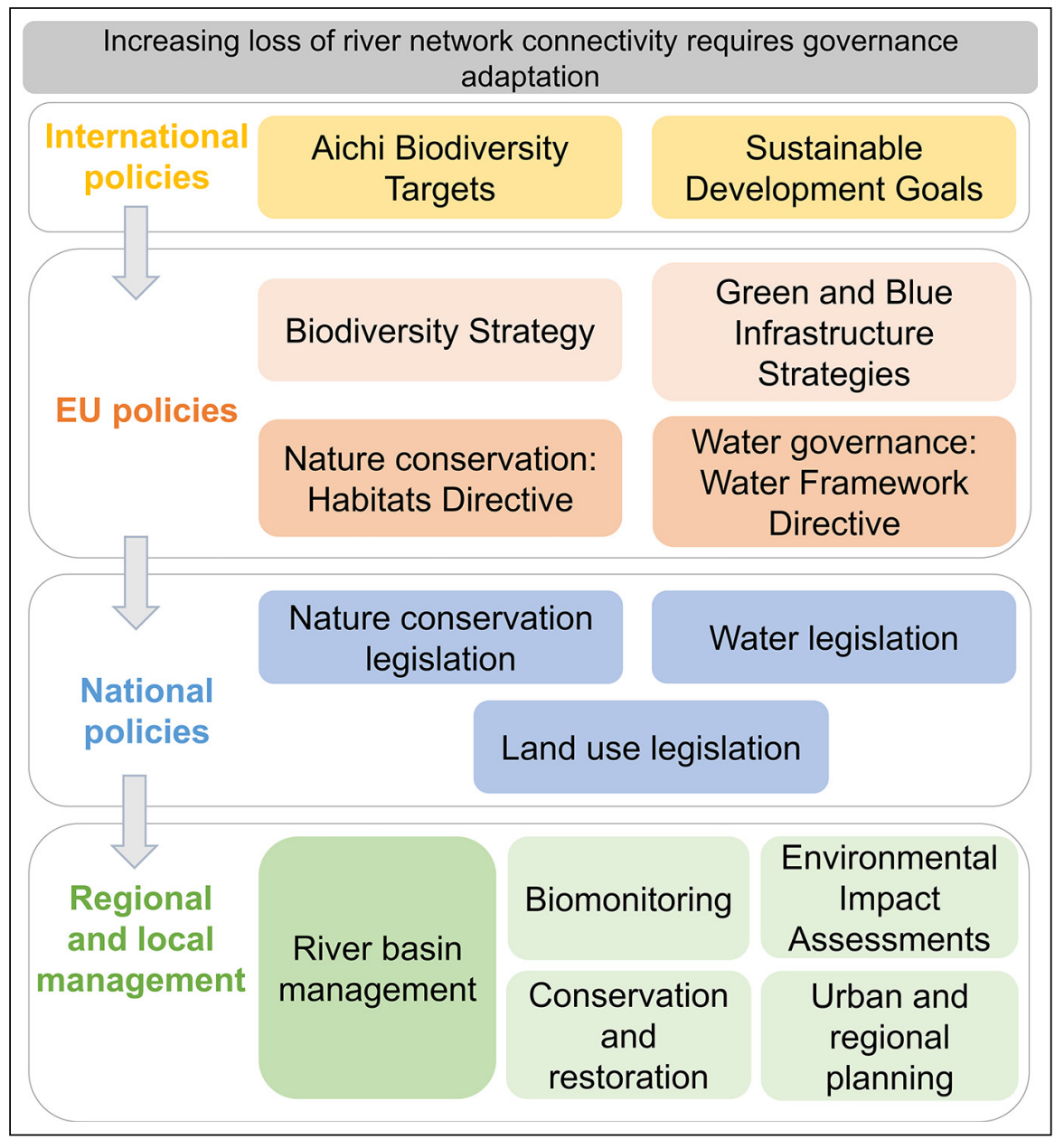

Figure 3. The current loss of river network connectivity worldwide will be exacerbated by climate change and affect the associated socioecological system. Legislation and regulations at all levels should adapt to these changes, including international agreements and related regional policies (here, examples from Europe), which form the basis of national-level regulations for water, nature conservation, and spatial planning.

allow dispersal of individuals after improving connectivity, conservation measures could be directed toward local habitat protection and assisted colonization (Lawler and Olden 2011).

Although vital to current conservation policies, protected areas rarely capture the complex spatial structure of river networks, rendering conservation of riverine biodiversity challenging (Carrizo et al.2017; Acreman et al.2020). Under a meta-system approach, protected areas within a catchment should be designed to ensure conservation of key sites across the network that promote metapopulation and metacommunity persistence. This could be achieved using prioritization methods in conservation planning that include the analysis of connectivity and spatial congruence of multiple species (Albert et al. 2017). For example, in river networks experiencing fragmentation through drying, selection of pivotal refugia that act as sources for dispersal is essential for ensuring protection of network-wide biodiversity (Hermoso et al.2013). Sites to be protected and/or restored across the network can be selected using information on the genetic diversity of a population and on the beta diversity components of a community (Table 1; Ruhí et al.2017; PazViñas et al.2018).

\section{Biomonitoring and restoration}

Most legislation protecting surface waters relies on local reach-scale evaluations of ecological status (Heino 2013). In the EU and the US, for instance, despite the management units of the EU Water Framework Directive and the US Clean Water Act defined as the river basin, these policies prescribe evaluation of different river reaches individually, based on the structural and/or functional properties of ecological assemblages; neither policy, however, explicitly encourages biological assessments at multiple spatial scales.

River biomonitoring methods typically compare the biotic community of a focal site with a reference value obtained from nonimpacted or least-impacted sites (Cid et al. 2020). Based on the local environmental conditions observed at those latter sites, the expected biotic community at the focal site (that is, the community that would have most likely existed at that location, in the absence of impacts) can then be predicted (Heino 2013; Cid et al. 2020). To consider regional processes in metacommunity dynamics, water managers could integrate proxies for dispersal based on spatial connectivity (eg fragmentation caused by dams, drying, or topographical barriers) and dispersal-related species traits into biomonitoring methods (Cid et al. 2020).

Improved consideration of the current and predicted levels of fragmentation may require the redesign of monitoring sites within a river network. For instance, whereas large dams are usually considered when selecting monitoring sites, fragmentation due to small barriers and potential drying events has often been overlooked (Erös et al. 2018). Assessing fragmentation within a river network and its potential interactive or additive effects with other stressors will improve predictions of ecological integrity using bioindicators.

Under a meta-system approach, restoration practices should include information on the regional species pool and the ability of species to locate restored habitats. Key sites acting as sources of colonizers should be identified, and their connectivity with restored river reaches should be evaluated (Heino et al. 2017). This is especially relevant when fragmentation is due to drying, as source sites within the regional species pool are typically located in dry season refugia (Datry et al.2014). To assess whether improvements in local diversity have positive effects on regional biodiversity, managers could incorporate indices such as taxonomic and functional beta, zeta, and gamma diversity (Panel 1; Table 1; Simons et al.2019). 
Table 1. Current metrics and indicators used in core environmental and biodiversity policies, and additional ones that could be implemented in a meta-system approach

\begin{tabular}{|c|c|c|c|}
\hline $\begin{array}{l}\text { Management action } \\
\text { and organizational } \\
\text { level of application }\end{array}$ & Policy examples & Current metrics/indicators & Additional metrics/indicators \\
\hline $\begin{array}{l}\text { Conservation/restoration, } \\
\text { (meta)population }\end{array}$ & $\begin{array}{l}\text { European Biodiversity Strategy and } \\
\text { Habitats Directive; US Endangered } \\
\text { Species Act; Australia Environment } \\
\text { Protection and Biodiversity } \\
\text { Conservation Act }\end{array}$ & $\begin{array}{l}\text { Species range }(\mathrm{km}) \text {; species occupancy area* }\left(\mathrm{km}^{2}\right) \text {; } \\
\text { species population size* (grid, individuals); species age } \\
\text { structure; species habitat area and quality }\end{array}$ & $\begin{array}{l}\text { Genetic diversity; gene flow; inbreeding; hybridization; } \\
\text { species effective dispersal; number and location of } \\
\text { metapopulation key habitats (eg refugia, dispersal routes); } \\
\text { area and quality of metapopulation key habitats; connectivity } \\
\text { between key habitats (eg dendritic connectivity index) }\end{array}$ \\
\hline $\begin{array}{l}\text { Biomonitoring/restoration, } \\
\text { (meta)community }\end{array}$ & $\begin{array}{l}\text { European Water Framework } \\
\text { Directive; US Clean Water Act; } \\
\text { Australia Water Act }\end{array}$ & $\begin{array}{l}\text { Local (alpha) taxonomic richness and diversity of } \\
\text { different taxonomic groups (ie macroinvertebrates, fish, } \\
\text { diatoms, macrophytes, riparian plants) }{ }^{\star *} \text {; species } \\
\text { environmental tolerance }{ }^{\star \star} \text {; number and richness of } \\
\text { alien species }{ }^{\star *} \text {; riparian vegetation cover }{ }^{\star *} \text {; riverbed } \\
\text { and riverbank morphology }{ }^{\star *}\end{array}$ & $\begin{array}{l}\text { Gamma species diversity; beta and zeta species diversity; } \\
\text { species dispersal capability (eg using organisms' traits as a } \\
\text { proxy for dispersal); species effective dispersal; } \\
\text { metacommunity key habitats area and quality (ie refugia, } \\
\text { dispersal routes); connectivity between key habitats (eg } \\
\text { dendritic connectivity index) }\end{array}$ \\
\hline $\begin{array}{l}\text { Ecosystem-based } \\
\text { management/restoration, } \\
\text { (meta)ecosystem and } \\
\text { ecosystem services }\end{array}$ & European Biodiversity Strategy ${ }^{\star \star \star}$ & $\begin{array}{l}\text { Nutrient load and retention; sediment transport and } \\
\text { retention; carbon storage, processing, and transport; } \\
\text { fish production (catch by fishermen); wood produced by } \\
\text { riparian forest; number and quality of swimming areas; } \\
\text { fishing reserves; most of the indicators listed above fall } \\
\text { within other categories (eg riparian vegetation cover) }\end{array}$ & $\begin{array}{l}\text { Leaf litter decomposition; ecosystem metabolism; food-web } \\
\text { structure; riparian stocks (eg using remote sensing); } \\
\text { number and location of hotspots of functioning (eg organic } \\
\text { matter and nutrient processing); number and location of } \\
\text { service-providing, service-connecting, and service- } \\
\text { benefiting areas }\end{array}$ \\
\hline
\end{tabular}

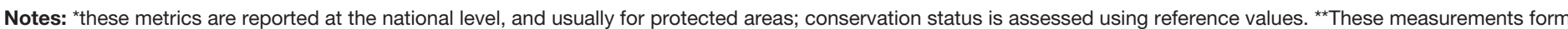

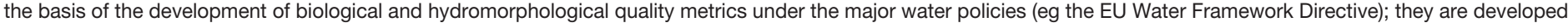
at the national level. ${ }^{\star \star \star}$ One primary target is the mapping and assessment of ecosystem services, which uses indicators from several sources.

\section{Toward a more holistic ecosystem-based management in rivers}

At the ecosystem level, there is a growing need for spatially explicit examinations of biogeochemical, hydromorphological, and ecological patterns and processes (Gounand et al. 2018; McCluney et al. 2014). Several prioritization tools are currently available for integrating spatial dynamics into conservation planning (eg Hermoso et al. 2013, 2018), and most policies and related guidance documents promote adaptive management that incorporates cross-ecosystem processes and scaledependency. However, implementation of these tools and principles remains rare (Acreman et al. 2020). Effectively integrating state-of-the-art ecological theory into environmental management will require research and capacity building. Monitoring programs should include measures of ecosystem processes across the river network, such as decomposition of leaf litter and ecosystem metabolism (Young et al. 2008) or measures of food web structure (Otto et al. 2018), which could help to identify functional hotspots (McClain et al. 2003). These measures could be systematically integrated into conservation planning. As different biodiversity facets, ecosystem processes, and ecosystem services may vary in their degree of spatial congruence across the river network, prioritization methods that integrate these variables simultaneously could be used to maximize their protection in a holistic way (Hermoso et al. 2018; Erős and Bányai 2020).

\section{Conclusions}

Meta-system theory represents a powerful framework for understanding the dynamics of populations, communities, and ecosystems, and for guiding conservation, biomonitoring, and restoration of increasingly fragmented river networks. Yet potential applications of this approach are only beginning to emerge, and many methodological and empirical developments are urgently needed to integrate this framework into environmental policies. Guidance based on meta-system theory could improve the quality of legislation and understanding of causes and effects across spatial scales, and constitute a major step toward sustainable, adaptive management of rivers in the Anthropocene. The relevance of this framework will be even greater in the future, as climate change and escalating human demand for water exacerbate the frequency and magnitude of extreme events, such as floods and droughts, thereby rapidly altering river connectivity and producing unprecedented river network fragmentation.

\section{Acknowledgements}

This manuscript is a product of the Alternet High Impact Action entitled "From meta-system theory to the sustainable, adaptive management of rivers in the Anthropocene". NC acknowledges the French research program Make Our Planet Great Again; SCJ acknowledges the German Federal Ministry of Education and Research through the GLANCE project (01LN1320A) and the Leibniz Competition project "Freshwater Megafauna Futures"; JH was supported by the Academy of Finland-funded project GloBioTrends; GS acknowledges the European Research Council through the project FLUFLUX (ERC-STG 716196); NB and MC-A acknowledge the CTM2017-89295-P project funded by the Spanish Ministerio de Economía, Industria y Competitividad - Agencia Estatal de Investigación and co-funded by the European Regional Development 
Fund; and TE acknowledges the National Multidisciplinary Laboratory for Climate Change 2020 program and the MTA KEP project. All authors, except TE, SCJ, and LS, were supported by the H2020 European Research and Innovation action Grant Agreement No869226 (DRYvER). We thank J Tonkin and N Wu for comments that substantially improved the manuscript.

\section{References}

Acreman M, Hughes KA, Arthington AH, et al. 2020. Protected areas and freshwater biodiversity: a novel systematic review distils eight lessons for effective conservation. Conserv Lett 13: e12684.

Albert CH, Rayfield B, Dumitru M, and Gonzalez A. 2017. Applying network theory to prioritize multispecies habitat networks that are robust to climate and land-use change. Conserv Biol 31: 1383-96.

Bellmore JR, Pess GR, Duda JJ, et al. 2019. Conceptualizing ecological responses to dam removal: if you remove it, what's to come? BioScience 69: 26-39.

Brown BL, Swan CM, Auerbach DA, et al. 2011. Metacommunity theory as a multispecies, multiscale framework for studying the influence of river network structure on riverine communities and ecosystems. J N Am Benthol Soc 30: 310-27.

Carrizo SF, Lengyel S, Kapusi F, et al. 2017. Critical catchments for freshwater biodiversity conservation in Europe: identification, prioritisation and gap analysis. J Appl Ecol 54: 1209-18.

Chen W and Olden JD. 2017. Designing flows to resolve human and environmental water needs in a dam-regulated river. Nat Commun 8: $1-10$.

Cid N, Bonada N, Heino J, et al. 2020. A metacommunity approach to improve biological assessments in highly dynamic freshwater ecosystems. BioScience 70: 427-38.

Creed IF, McKnight DM, Pellerin BA, et al. 2015. The river as a chemostat: fresh perspectives on dissolved organic matter flowing down the river continuum. Can J Fish Aquat Sci 72: 1272-85.

Datry T, Boulton AJ, Bonada N, et al. 2017. Flow intermittence and ecosystem services in rivers of the Anthropocene. J Appl Ecol 55: 353-64.

Datry T, Foulquier A, Corti R, et al. 2018. A global analysis of terrestrial plant litter dynamics in non-perennial waterways. Nat Geosci 11: 497-503.

Datry T, Larned ST, and Tockner K. 2014. Intermittent rivers: a challenge for freshwater ecology. BioScience 64: 229-35.

Döll P and Schmied HM. 2012. How is the impact of climate change on river flow regimes related to the impact on mean annual runoff? A global-scale analysis. Environ Res Lett 7: 014037.

Dudgeon D. 2019. Multiple threats imperil freshwater biodiversity in the Anthropocene. Curr Biol 29: R960-67.

Dudley PN. 2018. A salmonid individual-based model as a proposed decision support tool for management of a large regulated river. Ecosphere 9: e02074.

Erős T and Bányai Z. 2020. Sparing and sharing land for maintaining the multifunctionality of large floodplain rivers. Sci Total Environ 728: 138441.

Erős T, O’Hanley JR, and Czeglédi I. 2018. A unified model for optimizing riverscape conservation. J Appl Ecol 55: 1871-83.
Fausch KD, Torgersen CE, Baxter CV, and Li HW. 2002. Landscapes to riverscapes: bridging the gap between research and conservation of stream fishes. BioScience 52: 483-98.

Ferreira-Rodríguez N, Akiyama YB, Aksenova OV, et al. 2019. Research priorities for freshwater mussel conservation assessment. Biol Conserv 231: 77-87.

Fitzpatrick SW and Reid BN. 2019. Does gene flow aggravate or alleviate maladaptation to environmental stress in small populations? Evol Appl 12: 1402-16.

Fuller MR, Doyle MW, and Strayer DL. 2015. Causes and consequences of habitat fragmentation in river networks. Ann NY Acad Sci 1355: 31-51.

Fullerton AH, Anzalone S, Moran P, et al. 2016. Setting spatial conservation priorities despite incomplete data for characterizing metapopulations. Ecol Appl 26: 2558-78.

Gounand I, Harvey E, Little CJ, and Altermatt F. 2018. Metaecosystems 2.0: rooting the theory into the field. Trends Ecol Evol 33: 36-46.

Grill G, Lehner B, Thieme M, et al. 2019. Mapping the world's freeflowing rivers. Nature 569: 215-21.

Hagen M, Kissling WD, Rasmussen C, et al. 2012. Biodiversity, species interactions and ecological networks in a fragmented world. In: Jacob U and Woodward G (Eds). Advances in ecological research: global changes in multispecies systems, part 1. Cambridge, MA: Academic Press.

Hanski I. 1998. Metapopulation dynamics. Nature 396: 41-49.

Heino J. 2013. The importance of metacommunity ecology for environmental assessment research in the freshwater realm. Biol Rev 88: $166-78$.

Heino J, Alahuhta J, Ala-Hulkko T, et al. 2017. Integrating dispersal proxies in ecological and environmental research in the freshwater realm. Environ Rev 25: 334-49.

Hermoso V, Cattarino L, Linke S, and Kennard MJ. 2018. Catchment zoning to enhance co-benefits and minimize trade-offs between ecosystem services and freshwater biodiversity conservation. Aquat Conserv 28: 1004-14.

Hermoso V, Ward DP, and Kennard MJ. 2013. Prioritizing refugia for freshwater biodiversity conservation in highly seasonal ecosystems. Divers Distrib 19: 1031-42.

Jaeger KL, Olden JD, and Pelland NA. 2014. Climate change poised to threaten hydrologic connectivity and endemic fishes in dryland streams. P Natl Acad Sci USA 111: 13894-99.

Lawler JJ and Olden JD. 2011. Reframing the debate over assisted colonization. Front Ecol Environ 9: 569-74.

Leibold MA, Holyoak M, Mouquet N, et al. 2004. The metacommunity concept: a framework for multi-scale community ecology. Ecol Lett 7: 601-13.

Lewis SL and Maslin MA. 2015. Defining the Anthropocene. Nature 519: 171-80.

Markovic D, Carrizo S, Freyhof J, et al. 2014. Europe's freshwater biodiversity under climate change: distribution shifts and conservation needs. Divers Distrib 20: 1097-107.

Markovic D, Carrizo SF, Kärcher O, et al. 2017. Vulnerability of European freshwater catchments to climate change. Glob Change Biol 23: 3567-80. 
McClain ME, Boyer EW, Dent CL, et al. 2003. Biogeochemical hot spots and hot moments at the interface of terrestrial and aquatic ecosystems. Ecosystems 6: 301-12.

McCluney KE, Poff NL, Palmer MA, et al. 2014. Riverine macrosystems ecology: sensitivity, resistance, and resilience of whole river basins with human alterations. Front Ecol Environ 12: 48-58.

Otto SA, Kadin M, Casini M, et al. 2018. A quantitative framework for selecting and validating food web indicators. Ecol Indic 84: 619-31.

Paz-Viñas I, Loot G, Hermoso V, et al. 2018. Systematic conservation planning for intraspecific genetic diversity. P Roy Soc B-Biol Sci 285: 20172746.

Poff NL, Richter BD, Arthington AH, et al.2010. The ecological limits of hydrologic alteration (ELOHA): a new framework for developing regional environmental flow standards. Freshwater Biol 55: 147-70.

Rahel FJ and McLaughlin RL. 2018. Selective fragmentation and the management of fish movement across anthropogenic barriers. Ecol Appl 28: 2066-81.

Raymond PA, Hartmann J, Lauerwald R, et al. 2013. Global carbon dioxide emissions from inland waters. Nature 503: 355-59.

Reid AJ, Carlson AK, Creed IF, et al. 2019. Emerging threats and persistent conservation challenges for freshwater biodiversity. Biol Rev 94: 849-73.

Ruhí A, Catford JA, Cross WF, et al. 2019. Understanding the nexus between hydrological alteration and biological invasions. In: Sabater S, Elosegi A, and Ludwig R (Eds). Multiple stressors in river ecosystems. Amsterdam, the Netherlands: Elsevier.

Ruhí A, Datry T, and Sabo JL. 2017. Interpreting beta-diversity components over time to conserve metacommunities in highly dynamic ecosystems. Conserv Biol 31: 1459-68.

Schiesari L, Matias MG, Prado PI, et al. 2019. Towards an applied metaecology. Persp Ecol Conserv 17: 172-81.

Simons AL, Mazor R, Stein ED, and Nuzhdin S. 2019. Using alpha, beta, and zeta diversity in describing the health of streambased benthic macroinvertebrate communities. Ecol Appl 29: e01896.
Sousa V, Penha F, Pala I, et al. 2010. Conservation genetics of a critically endangered Iberian minnow: evidence of population decline and extirpations. Anim Conserv 13: 162-71.

Stewardson MJ and Guarino F. 2018. Basin-scale environmental water delivery in the Murray-Darling, Australia: a hydrological perspective. Freshwater Biol 63: 969-85.

Strecker AL and Brittain JT. 2017. Increased habitat connectivity homogenizes freshwater communities: historical and landscape perspectives. J Appl Ecol 54: 1343-52.

Swan CM and Brown BL. 2017. Metacommunity theory meets restoration: isolation may mediate how ecological communities respond to stream restoration. Ecol Appl 27: 2209-19.

Syrbe RU and Walz U. 2012. Spatial indicators for the assessment of ecosystem services: providing, benefiting and connecting areas and landscape metrics. Ecol Indic 21: 80-88.

Tonkin JD, Altermatt F, Finn DS, et al. 2018. The role of dispersal in river network metacommunities: patterns, processes, and pathways. Freshwater Biol 63: 141-63.

Tonkin JD, Stoll S, Sundermann A, and Haase P. 2014. Dispersal distance and the pool of taxa, but not barriers, determine the colonisation of restored river reaches by benthic invertebrates. Freshwater Biol 59: 1843-55.

Whittaker RH. 1972. Evolution and measurement of species diversity. Taxon 21: 213-51.

Young RG, Matthaei CD, and Townsend CR. 2008. Organic matter breakdown and ecosystem metabolism: functional indicators for assessing river ecosystem health. J N Am Benthol Soc 27: 605-25.

${ }^{9}$ Institut de Recerca de la Biodiversitat, Universitat de Barcelona, Barcelona, Spain; ${ }^{10}$ Norwegian Institute for Water Research, Oslo, Norway; ${ }^{11}$ Finnish Environment Institute, Environmental Policy Centre, Helsinki, Finland

This is an open access article under the terms of the Creative Commons Attribution-NonCommercial License, which permits use, distribution and reproduction in any medium, provided the original work is properly cited and is not used for commercial purposes. 